\title{
de Sayonara Leal Rádios Comunitárias no Brasil e na França: Democracia e Esfera Pública
}

1. Jornalista pela Universidade Federal de Sergipe (UFS), especialista em Associativismo pela Universidade Federal Rural de Pernambuco (UFR$\mathrm{PE})$, mestre em Ciências Sociais pela Universidade Federal da Bahia (UFBA) e, atualmente, doutoranda em Ciências Sociais na UFBA. sarah.palavra@ gmail.com
(Aracaju: Editora UFS, 2008)

\section{Sarah Roberta de Oliveira Carneiro ${ }^{1}$}

0 e adotarmos o princípio de que não devemos cair no reducionismo, ao percebermos que uma prática social, balizada por leis jurídicas, por não as seguir à risca, não necessariamente se despe de todas as suas propriedades, visto que práticas sociais podem ser perpassadas por diferentes lógicas de ação, fazendo-as dispor de conotações diversas; sem dúvida, as análises sociológicas tenderão a salvaguardar a possibilidade de o objeto de estudo circunscrito pela pesquisa - vir a ser tratado sob um enfoque que realmente abarque pertinentes relativizações e, deste modo, os resultados alcançados podem mostrar-se muito mais próximos da realidade observada, invariavelmente repleta de contradições.

É bom que parece ter sido essa a diretriz que orientou a abordagem de Sayonara Leal, professora vinculada ao Departamento de Sociologia da Universidade de Brasília (UnB) e coordenadora do Laboratório de Políticas de Comunicação (Lapcom), em seu livro Rádios comunitárias no Brasil e na França: democracia e esfera pública, fruto da sua tese de doutoramento e que lança a seguinte questão: "em que medida as rádios associativas na França e as rádios comunitárias no Brasil se configuram como espaços democrático-participativos e de manifestação de esferas públicas, compreendidos, nos casos estudados, como locus perpassados por diferentes lógicas de ação?" (p. 399).

Essa interrogação dispõe de terreno fértil para ser formulada, posto que as rádios comunitárias, como lembra Sayonara, apontam para um processo de democratização de espaços comunicativos, pois se verifica "a manifestação de uma comunicação pública que media opiniões, necessidades e interesses de uma 'comunidade', a partir do mecanismo da participação, em um espaço concebido como democrático" (p. 30). E, para responder seu questionamento, a autora empreendeu uma análise comparativa, cujo ponto de partida foi a investigação empírica ancorada no estudo em profundidade de cinco rádios brasileiras e cinco francesas, as quais foram observadas, tendo a questão de pesquisa sido 
orientada pelas categorias participação, pluralidade, diálogo, reconhecimento e lógicas de ação.

Para fins de pesquisa, além de vislumbrar as rádios comunitárias como espaço comunicativo com potencial democrático, Sayonara ressalta que, no âmbito da sociologia política, as novas maneiras de participação no espaço público, a partir da palavra pública individualizada, têm sido interpretadas como a tradução de um fenômeno que se relaciona com os atuais pressupostos de espaços públicos plurais, e estes, por sua vez, "abrigam formas autênticas e autônomas de leituras e reinterpretações de mazelas sociais e eventos ordinários que constituem a vida cotidiana de coletividades" (p. 81).

As dez rádios, comparadas por Sayonara sob a observação de quatro eixos temáticos - a saber: a rádio como espaço democrático-participativo; a rádio como espaço plural e de lutas por reconhecimento; a rádio como espaço de comunicação sem fins lucrativos; e a rádio como espaço de diferentes lógicas de ação - , foram escolhidas pela estudiosa no universo das 37 emissoras (22 francesas e 15 brasileiras) pesquisadas ao longo do seu trabalho, o qual Ihe exigiu aplicação de questionários, realização de entrevistas episódicas e semiestruturadas com os membros das rádios, a escuta minuciosa das programações radiofônicas e o exercício da análise documental, que se fez necessário, por exemplo, na leitura dos relatórios de atividades produzidos pela direção das rádios francesas para seu respectivo Comitê Técnico (CTR), que é uma espécie de braço regional do Conselho Superior Audiovisual (CSA), autoridade administrativa atrelada ao Estado, mas que usufrui de certa independência e, dentre outras funções, gere os poderes normativo, de nominação, sanção, controle e autorização dos operadores do audiovisual.

E claro que, além dos mencionados recursos metodológicos, a pesquisadora leu uma vasta bibliografia, a qual lhe pôs em contato com significativos aportes teóricos, como os conceitos de mundos sociais ou cités, de Boltanski e Thévenot (1991), cujas ideias se converteram em preciosas pistas para que o estudo empreendido por Sayonara não se restringisse a um conjunto de constatações a respeito da não obediência das rádios investigadas ao que delibera, no Brasil, a Lei 9.612/98 e, na França, a lei francesa do audiovisual. Segundo a autora, na França, "não há uma lei específica que disponha sobre rádios locais não lucrativas, mas uma lei geral que trata de todo o setor audiovisual, a chamada Lei de Liberdade de Comunicação (2000-719, de $1^{\circ}$ de agosto de 2000), mais precisamente seus artigos 28 e 80" (p. 126). Nesta lei, não se emprega a terminologia "radiodifusão comunitária", para se referir as rádios locais não-comerciais, mas sim o termo rádio associativa.

Apontando distinções dessa natureza na comparação que desenvolveu, Sayo- 
nara é bastante criteriosa na formulação das suas assertivas e desenvolve uma pesquisa que não está demasiadamente preocupada em localizar as deformidades de práticas políticas das rádios comunitárias, por isso, lança um olhar que valoriza aquelas características das rádios, alinhadas à configuração da esfera pública, sem, no entanto, negar-se a captar os limites e paradoxos que essas rádios apresentam, na medida em que, nas entrevistas que ela realizou e na escuta das programações radiofônicas que fez, verificou algumas distorções, por exemplo, no que se refere à abertura ao uso da palavra por parte do tecido associativo onde as rádios estudadas estão inseridas, pois, de um modo geral, suas diretorias, que costumam se preocupar com o profissionalismo daqueles que fazem as emissões radiofônicas, as enxergam como rádios de propriedade privada, sem fins lucrativos que prestam um serviço público.

Esta percepção manifestada pelos diretores e também pelos locutores não é aleatória, mostra a autora, visto que as rádios francesas e brasileiras não dispõem de uma localização confortável no quadro normativo que rege as mídias nesses países. Elas formam um setor específico da radiodifusão tanto no Brasil quanto na França, pois figuram ao lado das emissoras públicas e comerciais. Nesse sentido, Sayonara aponta para a urgência da revisão das leis, sobretudo, no Brasil, onde não há investimento de recursos públicos na área, ao contrário da França, que conta com o Fundo de Suporte à Emissão Radiofônica (FSER), que pode ser investido na manutenção da emissora, compra e renovação de equipamentos técnicos e instalações.

Do mesmo modo que tece uma relação entre as imprecisões das leis e a forma como "os detentores" das rádios as notam, ou seja, como espaço privado que oferece um serviço público, Sayonara adentra às razões que explicam a não adesão das rádios exclusivamente aos pressupostos da esfera pública, na medida em que as vislumbra como "um mundo social singular coabitado por diferentes lógicas de ação" (p. 25). Por isso, ela compreende que as oscilações de comportamento das rádios, que ora se voltam para temáticas comunitárias, ora para o interesse privado daqueles que as compõem, não invalida completamente sua potencialidade para a manifestação da esfera pública.

Em seu entendimento, "o uso social das rádios comunitárias como recurso de comunicação oferece uma alternativa legítima de populações carentes e locais de desenvolverem um sistema próprio de comunicação e interação com a realidade regional" (p. 26). Sendo assim, é possível afirmar que a autora vincula-se a uma proposta de percepção ampliada daquilo que tem caráter momentâneo, pontual e até epifânico, uma vez que não desmerece a atuação democrática das rádios, por menor que possa parecer. A democracia, inclusive, é uma categoria anunciada no título do trabalho de Sayonara e que, já na primeira parte do livro, é alvo de reflexões que apontam para as limitações da democracia representa- 
tiva, mas com o zelo de acolherem suas realizações. A autora frisa a necessidade da democracia se expandir, o que exige a valorização de práticas comunicativas derivadas das manifestações socioculturais espontâneas da sociedade civil, não provenientes do mercado, e que venham a galgar espaços oficiais de articulação da política, costumeiramente preenchidos por aqueles sujeitos que são escolhidos mediante realização de procedimentos democráticos orientados pela maioria. Sayonara salienta a reinvenção da democracia, além de destacar o permanente redimensionamento que marca a relação entre Estado, democracia e sociedade civil. E, do mesmo modo que ela se dedica ao manuseio do conceito de democracia, também se preocupa em tratar as noções de comunidade, e, nesse caso, posiciona-se alertando para a adoção de um senso comunitário, relacionado a processos culturais e de comunicação.

Não escapa aos procedimentos de pesquisa de Sayonara a contextualização do surgimento das rádios livres na Europa e na América Latina, mas ela faz questão de evidenciar que as rádios comunitárias e as rádios associativas não podem ser tomadas como rádios livres, uma vez que estas estão tradicionalmente associadas à contestação, seus registros carregam um forte apelo militante e suas ações são impregnadas de um viés esquerdista.

A conexão muito bem imbricada que Sayonara tece entre os conceitos inseridos em sua pesquisa revela o grau de labor da sua empreitada, o que rende ao leitor boas sínteses, a exemplo da que é formulada sobre a esfera pública, uma vez que a autora revisa o conceito, nos termos de Arendt e Habermas, examina Kant, na perspectiva de observar o tom do que vem a ser público, e diz quando a esfera pública se realiza, ao afirmar que "se viabiliza pela exposição de elaborações subjetivas que se tornam públicas ao serem objetivadas no ato da palavra pronunciada na cena pública" (p. 102).

Sendo assim, Sayonara retoma o pensamento de Habermas sobre a ação comunicativa, como uma ação social moralmente fundamentada e competente para subsidiar processos de reconhecimento; nesse sentido, ou seja, do alcance do reconhecimento, a autora avança trazendo contribuições de outros pensadores, como Nancy Fraser (2005), Honnet (2003) e Bauman (2000). Nesse quesito, a autora localiza distinções entre a dinâmica das cinco rádios brasileiras que pesquisou e que estão concentradas em cidades satélites do Distrito Federal e as cinco rádios associativas francesas, cujos endereços se localizam na região NordPas-de-Calais.

A autora escreve: “(...) enquanto na França a rádio associativa, muitas vezes, se coloca entre indivíduo e Estado, tentando aproximar um e outro, no Brasil a rádio comunitária, em muitos casos, assume atribuições do ente estatal, sobretudo, quando promove ações assistencialistas em direção a populações carentes". 
Esta passagem e muitas outras contidas no livro ilustram a cautela que Sayonara teve em sua pesquisa, no que se refere ao registro das similitudes e das diferenças encontradas entre as rádios, quando postas em comparação.

Afinal, investir na análise comparativa conduziu a autora a um extremo cuidado metodológico para que não viesse a colocar em patamares muito próximos realidades diferentes como se não fossem. Sayonara, tendo especial zelo com os dados com os quais se deparou, conseguiu produzir uma pesquisa de doutorado que se tornou livro. E sua leitura amplia nossa percepção sobre as rádios comunitárias, ao nos apresentar algumas de suas características como, por exemplo, dificuldades financeiras enfrentadas, forte incidência do voluntariado na produção radiofônica e a existência de uma grade de programação que tem boa parte ocupada por emissões musicais, além de nos mostrar o quanto a democracia pode estar, em meio a outros sentidos, viva no ambiente das rádios.

O livro está dividido em três partes, sendo a primeira dedicada ao arcabouço conceitual sobre, principalmente, democracia, esfera pública, comunidade, reconhecimento e lógicas de ação; a segunda, voltada à explicitação detalhada das rádios estudadas e à análise comparativa entre elas, e a última, posta como a conclusão do trabalho, a qual reconhece que, embora as rádios não incorporem plenamente o modelo ideal da esfera pública, não se pode desmerecer seus feitos como espaço que promove, sim, interações sociais valiosas que se aproximam do exercício da democracia e da expressão. As mais de 400 páginas escritas por Sayonara nos revelam, portanto, pontos críticos das rádios, como a existência das lógicas comercial e mercantil, mas ao mesmo tempo nos convida a olharmos as rádios como espaços plurais que registram experiências capazes de se conectarem com o significado da esfera pública.

Rádios comunitárias no Brasil e na França: democracia e esfera pública nos faz ver que a palavra dita numa rádio comunitária serve para aproximar pessoas que partilham de uma mesma insatisfação no que se refere ao papel do Estado, por exemplo, assim como evidencia o quanto uma campanha solidária, realizada por algum programa radiofônico, consegue solucionar emergencialmente os problemas de uma família com frio. O livro nos mostra como as práticas discursivas das rádios comunitárias podem remeter aos pressupostos da esfera pública, favorecendo a interação entre diferentes atores sociais, através da enunciação dos seus dilemas, opiniões, opções musicais e pensamentos. Então, há de se ter cuidado no olhar avaliativo lançado para uma rádio comunitária, pois esta pode estar cumprindo, um pouco que seja, seu papel de espaço democráticoparticipativo e de manifestação da esfera pública e, ao que parece, esse feito pode ser mais transformador do que o silêncio. 